\title{
Exhaled Nitric Oxide in Patients with Stable Chronic Obstructive Pulmonary Disease: Clinical Implications of the Use of Inhaled Corticosteroids
}

\author{
Yong Suk Jo, M.D. ${ }^{1 *}{ }^{(\mathbb{D}}$, Junsu Choe, M.D. ${ }^{2 *}{ }^{*}$, Sun Hye Shin, M.D. ${ }^{2}$, Hyeon-Kyoung Koo, M.D. ${ }^{3}$, \\ Won-Yeon Lee, M.D. ${ }^{4}$, Yu Il Kim, M.D. ${ }^{5}$, Seung Won Ra, M.D. ${ }^{6}$, Kwang Ha Yoo, M.D. ${ }^{7}$, Ki Suck Jung, \\ M.D. ${ }^{8}$, Hye Yun Park, M.D. ${ }^{2}$ and Yong-Bum Park, M.D. ${ }^{9}{ }^{\mathbb{D}}$ \\ *Author affiliations appear at the end of this article.
}

Background: Fractional exhaled nitric oxide (FeNO) is regarded as a potential biomarker for identifying eosinophilic inflammation. We aimed to evaluate the clinical implication of FeNO and its influence on inhaled corticosteroids (ICS) prescription rate in Korean chronic obstructive pulmonary disease (COPD) patients.

Methods: FeNO level and its association with clinical features were analyzed. Changes in the prescription rate of ICS before and after FeNO measurement were identified.

Results: A total of 160 COPD patients were divided into increased ( $\geq 25$ parts per billion [ppb], $\mathrm{n}=74)$ and normal $(<25$ ppb, $\mathrm{n}=86$ ) FeNO groups according to the recommendations from the American Thoracic Society. Compared with the normal FeNO group, the adjusted odds ratio for having history of asthma without wheezing and with wheezing in the increased FeNO group were 2.96 (95\% confidence interval [CI], 1.40-6.29) and 4.24 (95\% CI, 1.37-13.08), respectively. Only 21 out of 74 patients (28.4\%) with increased FeNO prescribed ICS-containing inhaler and 18 of 86 patients (20.9\%) with normal FeNO were given ICS-containing inhaler. Previous exacerbation, asthma, and wheezing were the major factors to maintain ICS at normal FeNO level and not to initiate ICS at increased FeNO level.

Conclusion: Increased FeNO was associated with the history of asthma irrespective of wheezing. However, FeNO seemed to play a subsidiary role in the use of ICS-containing inhalers in real-world clinics, which was determined with prior exacerbation and clinical features suggesting Th2 inflammation.

Keywords: Chronic Obstructive Pulmonary Disease; Fractional Exhaled Nitric Oxide; Inhaled Corticosteroids

Address for correspondence: Yong-Bum Park, M.D.

Division of Pulmonary, Allergy, and Critical Care Medicine, Department of Internal Medicine, Hallym University Kangdong Sacred Heart Hospital, 150 Seongan-ro, Gangdong-gu, Seoul 05355, Korea

Phone: 82-2-2224-2754, Fax: 82-2-2224-2569, E-mail: bfspark2@gmail.com

Address for correspondence: Hye Yun Park, M.D.

Division of Pulmonary and Critical Care Medicine, Department of Medicine, Samsung Medical Center, Sungkyunkwan University School of Medicine, 81 Irwon-ro, Gangnam-gu, Seoul 06351, Korea

Phone: 82-2-3410-3429, Fax: 82-2-3410-3849, E-mail: hyeyunpark@skku.edu

*Yong Suk Jo and Junsu Choe contributed equally to this work.

Received: Jun. 7, 2019, Revised: Sep. 6, 2019, Accepted: Oct. 18, 2019, Published online: Nov. 7, 2019

(c) It is identical to the Creative Commons Attribution Non-Commercial License (http://creativecommons.org/licenses/by-nc/4.0/). 


\section{Introduction}

Chronic obstructive pulmonary disease (COPD) is a progressive inflammatory airway disease characterized by persistent airflow limitation ${ }^{1}$. For patients with stable symptomatic COPD, inhaled bronchodilators are the mainstay of treatment to control symptoms ${ }^{1}$. Although the use of inhaled corticosteroids (ICS) is recommended only for COPD patients who experience frequent exacerbations, discrepancies have often been reported among recommendations and actual clinical practice, where ICS, especially in combination with a long-acting beta-agonist, are widely used in the management of COPD patients $^{2-4}$. The overuse of ICS as maintenance therapy clearly raises a concern due to the increased risk for pneumonia and adverse effects of long-term use of ICS ${ }^{5-7}$. Thus, it is imperative to investigate clinical features and indicators to predict a favorable ICS response in patients with COPD.

Neutrophilic airway inflammation is a prominent feature in most COPD patients and related to the degree of airflow limitation ${ }^{8}$. However, increased eosinophilic inflammation has been reported in a subset of patients with COPD, and approximately $20 \%$ of smokers with COPD have a Th2-high signature $^{9-11}$. These patients exhibit a greater response to shortterm oral and ICS treatment ${ }^{12,13}$; however, sputum specimens have limited value in clinical applications because of contamination risk and difficulty in collection. Accordingly, blood eosinophil count has emerged as an alternative biomarker to predict which subset of patients will benefit from steroid treatment ${ }^{14-16}$. Although blood eosinophil count over 300 cells $/ \mu \mathrm{L}$ is regarded as threshold for predicting high likelihood of benefit with ICS ${ }^{17,18}$, variability on serial blood eosinophil counts examination may be problematic ${ }^{19,20}$.

Another simple and noninvasive measurement reflecting eosinophilic airway inflammation is fractional exhaled nitric oxide (FeNO). In several studies, FeNO has demonstrated a correlation with eosinophilic airway inflammation ${ }^{21,22}$ and a recent study reported that FeNO measurement is useful in patients with non-specific respiratory symptoms to predict response to $\mathrm{ICS}^{23}$. Despite the increasing attention devoted to FeNO in clinics, there are limited data regarding clinical characteristics related to eosinophilic airway inflammation and high FeNO levels in patients with stable COPD. Moreover, research investigating clinician behavior, such as addition or withdrawal of ICS based on FeNO value, is not available. Thus, we aimed to investigate the relationship between history of asthma and/or wheezing and increased FeNO levels in patients with stable COPD. We further assessed whether FeNO values affect ICS prescription in a real-world setting.

\section{Materials and Methods}

\section{Patients}

The Korea COPD Subgroup Registry and Subtype Research (KOCOSS) (registered with ClinicalTrial.gov identifier NCT02800499) is an ongoing, multi-center, prospective observational cohort study, launched in December 2011, with 48 centers in Korea participating. Details of the KOCOSS study have been previously published ${ }^{24}$. Participants aged $\geq 40$ years and post-bronchodilator forced expiratory volume in 1 second $\left(\mathrm{FEV}_{1}\right) /$ forced vital capacity $<70 \%$ were included in the COPD cohort. In 2016, the KOCOSS protocol was updated to include FeNO measurement, and 160 patients from the KOCOSS cohort, whose FeNO was measured during stable period of COPD was identified from the KOCOSS cohort. All study procedures were performed in accordance with the Declaration of Helsinki and relevant guidelines, and informed consent was obtained from all participants before enrollment. The study protocol was approved by the Institutional Review Board of Samsung Medical Center (IRB No. 2018-05-055-001).

\section{Clinical measurements}

At initial evaluation, demographic and clinical data, including, age, sex, and body mass index, smoking status, history of physician-diagnosed asthma, subjective wheezing, modified Medical Research Council dyspnea scale, self-perceived quality of life status, assessed using the COPD assessment test, were collected by physicians or trained nurses using electronic case-report forms. A blood sample was collected, and blood eosinophil and total IgE were quantified and verified.

Spirometry was performed using standardized equipment according to the recommendations of the American Thoracic Society (ATS) and the European Respiratory Society (ERS) guidelines $^{25}$. Based on the ATS/ERS guidelines, spirometry was performed before and after a 15-minute delay of the inhalation of 2 puffs of salbutamol to assess bronchodilator response (BDR). The predicted percentage values for the results of spirometry were calculated from the equation developed in Korean populations ${ }^{26}$.

\section{Measurement of FeNO}

According to the ATS guideline ${ }^{27}$, FeNO levels were measured by asking patients to inhale a maximum amount of air outside the valve and then exhale into the valve which in turn was connected to a chemiluminescent NO analyzer (NIOX MINO, Aerocrine AB, Solna, Sweden) or NObreath (Bedfont Scientific, Maidstone, UK), depending on the device each hospital was equipped with. FeNO levels were measured twice to verify reproducibility and validity; the mean value of FeNO was subsequently calculated. A FeNO $<25$ parts per billion 
(ppb) was regarded as normal and $\geq 25 \mathrm{ppb}$ as increased, in accordance with the recommendations from the $\mathrm{ATS}^{27}$.

\section{Statistical analysis}

Data are expressed as mean \pm standard deviation, or absolute number with percentages unless otherwise indicated. To analyze baseline characteristics, the Pearson's chi-squared test was used for categorical variables, while the Student's t-test or Fisher's exact test was used for continuous variables. To assess the correlation between blood eosinophil and FeNO values, Pearson correlation analysis was performed. The degree of agreement between two values is expressed as the correlation coefficient, $r$, for which a positive value indicates a positive correlation and the higher the value, the stronger the correlation. Thus, the clinical characteristics of COPD patients according to FeNO level were analyzed using logistic regression analysis based on a FeNO value of 25 ppb. The multivariable logistic regression analyses were adjusted for covariates such as age, sex, smoking status and $\mathrm{FEV}_{1}<50 \%$ predicted.

All analyses were two-sided, and a p-value of $<0.05$ was considered to be statistically significant. All analyses were performed using STATA version 13.1 (StataCorp., College Station, TX, USA)

\section{Results}

\section{Patient characteristics}

The mean age of the 160 COPD patients was 70.5 years and most $(n=150,93.9 \%)$ were male and current or ex-smokers $(\mathrm{n}=153,95.6 \%)$. Mean FeNO level was $27.1 \pm 17.3 \mathrm{ppb}$ and mean eosinophil count was $190.8 \pm 161.9$ cells $/ \mathrm{mL}$ (Table 1 ).

Using cut-off value of $25 \mathrm{ppb}, 74$ patients (46.3\%) had increased FeNO. Those patients were more likely to have a history of asthma ( $37.8 \%$ vs. $19.8 \%, \mathrm{p}=0.011)$ or a history of asthma with accompanied wheezing ( $18.9 \%$ vs. $7.0 \%, \mathrm{p}=0.023$ ) compared with those with normal FeNO levels.

The severity of respiratory symptoms, self-perceived disease-specific quality of life status, and lung function were not significantly different between the two groups. Although patients with increased FeNO level demonstrated a positive BDR more frequently, the difference was not statistically significant (Table 2). Blood eosinophil count was higher in the increased FeNO group than in those with normal FeNO level without statistical significance $(207.2$ cells $/ \mathrm{mL}$ vs. 176.6 cells $/ \mathrm{mL}$, $\mathrm{p}=0.242$ ) (Table 2). The level of FeNO and blood eosinophil count demonstrated a positive but no significant correlation (Figure 1).

\section{Association between increased FeNO level and history of asthma and wheezing}

To investigate the association between increased FeNO and history of asthma with or without subjective wheezing, patients were categorized in to three groups according to the presence of history of asthma and subjective wheezing: patients with wheezing $(\mathrm{n}=50)$, patients with asthma without wheezing $(\mathrm{n}=45)$, and patients with both asthma and wheezing $(\mathrm{n}=20)$. Increased FeNO level was associated with a history

Table 1. Clinical characteristics of all included patients $(\mathrm{n}=160)$

\begin{tabular}{|c|c|}
\hline Characteristic & Value \\
\hline Male sex & $150(93.8)$ \\
\hline Age, yr & $70.5 \pm 7.6$ \\
\hline Body mass index, $\mathrm{kg} / \mathrm{m}^{2}$ & $23.2 \pm 3.1$ \\
\hline \multicolumn{2}{|l|}{ Smoking status } \\
\hline Current smoker & $43(26.9)$ \\
\hline Ex-smoker & $110(68.7)$ \\
\hline Never smoker & $7(4.4)$ \\
\hline Smoking, pack-years & $41.8 \pm 25.9$ \\
\hline CAT & $13.7 \pm 8.3$ \\
\hline $\mathrm{mMRC}$ & $1.2 \pm 0.9$ \\
\hline 6MWD, m & $391.6 \pm 116.2$ \\
\hline FeNO & $27.1 \pm 17.3$ \\
\hline \multicolumn{2}{|l|}{ Blood eosinophil count } \\
\hline Percentage & $2.9 \pm 2.3$ \\
\hline Cells, $/ \mu \mathrm{L}$ & $190.8 \pm 161.9$ \\
\hline Serum total IgE & $330.5 \pm 635.8$ \\
\hline Previous diagnosis of asthma & $45(28.1)$ \\
\hline \multicolumn{2}{|l|}{ Lung function } \\
\hline $\mathrm{FEV}_{1}, \mathrm{~L}$ & $1.86 \pm 0.68$ \\
\hline $\mathrm{FEV}_{1}, \%$ predicted & $66.4 \pm 20.3$ \\
\hline FVC, L & $3.51 \pm 0.81$ \\
\hline FVC, \% predicted & $88.7 \pm 15.8$ \\
\hline $\mathrm{FEV}_{1} / \mathrm{FVC}, \%$ & $52.0 \pm 11.5$ \\
\hline BDR positivity* & $4(2.5)$ \\
\hline
\end{tabular}

Values are presented as number (\%) or mean \pm standard deviation unless otherwise indicated.

*Positive BDR defined as elevated $\mathrm{FEV}_{1}>12 \%$ and $>200 \mathrm{~mL}$ from baseline $\mathrm{FEV}_{1}$ after the inhalation of $200 \mu \mathrm{g}$ of salbutamol.

CAT: chronic obstructive pulmonary disease assessment test; mMRC: modified Medical Research Council; 6MWD: 6-minute walk distance; $\mathrm{FeNO}$ : fractional exhaled nitric oxide; $\mathrm{FEV}_{1}$ : forced expiratory volume in 1 second; FVC: forced vital capacity; BDR: bronchodilator response. 
Table 2. Clinical characteristics according to FeNO levels

\begin{tabular}{|c|c|c|c|}
\hline Characteristic & FeNO $<25$ ppb & FeNO $\geq 25$ ppb & p-value \\
\hline No. of patients & $86(53.8)$ & $74(46.3)$ & \\
\hline Male sex & $80(93.0)$ & $70(94.6)$ & 0.682 \\
\hline Age, yr & $70.7 \pm 6.4$ & $70.3 \pm 8.9$ & 0.760 \\
\hline Body mass index, $\mathrm{kg} / \mathrm{m}^{2}$ & $23.2 \pm 3.3$ & $23.3 \pm 3.0$ & 0.849 \\
\hline \multicolumn{4}{|l|}{ Smoking status } \\
\hline Current smoker & $27(31.4)$ & $16(21.6)$ & \\
\hline Ex-smoker & $55(64.0)$ & $55(74.3)$ & 0.356 \\
\hline Never smoker & $4(4.6)$ & $3(4.1)$ & \\
\hline Smoking pack-year & $42.9 \pm 26.1$ & $40.4 \pm 25.8$ & 0.557 \\
\hline Previous exacerbation & $12(14.5)$ & $7(10.3)$ & 0.443 \\
\hline CAT score $\geq 10$ & $52(60.5)$ & $52(70.3)$ & 0.195 \\
\hline $\mathrm{mMRC} \geq 1$ & $67(77.9)$ & $64(86.5)$ & 0.160 \\
\hline $\mathrm{mMRC} \geq 2$ & $28(32.6)$ & $25(33.8)$ & 0.870 \\
\hline Previous diagnosis of asthma & $17(19.8)$ & $28(37.8)$ & 0.011 \\
\hline Subjective wheezing & $27(31.8)$ & $23(31.5)$ & 0.972 \\
\hline History of asthma and wheezing & $6(7.0)$ & $14(18.9)$ & 0.023 \\
\hline FeNO, ppb & $15.7 \pm 5.4$ & $40.3 \pm 16.9$ & $<0.001$ \\
\hline Blood eosinophil , \% & $2.5 \pm 2.2$ & $3.3 \pm 2.2$ & 0.032 \\
\hline$\geq 3 \%$ & $27(31.4)$ & $32(43.2)$ & 0.121 \\
\hline Blood eosinophil, cells $/ \mu \mathrm{L}$ & $176.6 \pm 181.4$ & $207.2 \pm 135.4$ & 0.242 \\
\hline$\geq 300$ cells $/ \mu \mathrm{L}$ & $16(18.6)$ & $20(27.0)$ & 0.203 \\
\hline Serum total IgE & $425.7 \pm 826.3$ & $223.3 \pm 271.6$ & 0.051 \\
\hline \multicolumn{4}{|l|}{ Lung function } \\
\hline $\mathrm{FEV}_{1}, \mathrm{~L}$ & $1.82 \pm 0.68$ & $1.90 \pm 0.68$ & 0.455 \\
\hline $\mathrm{FEV}_{1}, \%$ predicted & $67.0 \pm 21.6$ & $65.6 \pm 18.9$ & 0.673 \\
\hline FVC, L & $3.45 \pm 0.81$ & $3.59 \pm 0.80$ & 0.299 \\
\hline FVC, \% predicted & $89.1 \pm 16.4$ & $88.2 \pm 15.1$ & 0.726 \\
\hline $\mathrm{FEV}_{1} / \mathrm{FVC}, \%$ & $52.0 \pm 11.4$ & $52.0 \pm 11.8$ & 0.990 \\
\hline $\mathrm{FEV}_{1}, \%$ predicted $<50 \%$ & $19(22.1)$ & $15(20.3)$ & 0.779 \\
\hline BDR positivity* & $1(1.2)$ & $3(4.1)$ & 0.243 \\
\hline \multicolumn{4}{|c|}{ GOLD classification according to GOLD 2014 strategy groups } \\
\hline A & $28(35.6)$ & $19(25.7)$ & \\
\hline B & $36(41.9)$ & $33(44.6)$ & 0.241 \\
\hline $\mathrm{C}$ & $3(3.5)$ & $0(0)$ & \\
\hline $\mathrm{D}$ & $19(22.1)$ & $22(29.7)$ & \\
\hline
\end{tabular}

Values are presented as number (\%) or mean \pm standard deviation.

*Positive BDR defined as elevated $\mathrm{FEV}_{1}>12 \%$ and $>200 \mathrm{~mL}$ from baseline $\mathrm{FEV}_{1}$ after the inhalation of $200 \mu \mathrm{g}$ of salbutamol.

FeNO: fractional exhaled nitric oxide; ppb: parts per billion; CAT: chronic obstructive pulmonary disease assessment test; mMRC: modified Medical Research Council; $\mathrm{FEV}_{1}$ : forced expiratory volume in 1 second; FVC: forced vital capacity; BDR: bronchodilator response; GOLD: Global Initiative for Chronic Obstructive Lung Disease. 
of asthma (odds ratio [OR], 2.47; 95\% confidence interval [CI], $1.22-5.02 ; \mathrm{p}=0.012$ ). When subjective wheezing was accompanied by asthma, the OR in patients with increased FeNO was 3.11 (95\% CI, 1.23-8.57; $\mathrm{p}=0.028$ ). These associations persisted after adjustments for age, sex, smoking status, and $\mathrm{FEV}_{1}<50 \%$ predicted (adjusted OR, 2.96 [95\% CI, 1.40-6.29]; $\mathrm{p}=0.005$ for a history of asthma and adjusted OR, 4.24 [95\% CI, 1.37-13.08]; $\mathrm{p}=0.012$ for a history of asthma with wheezing). However,

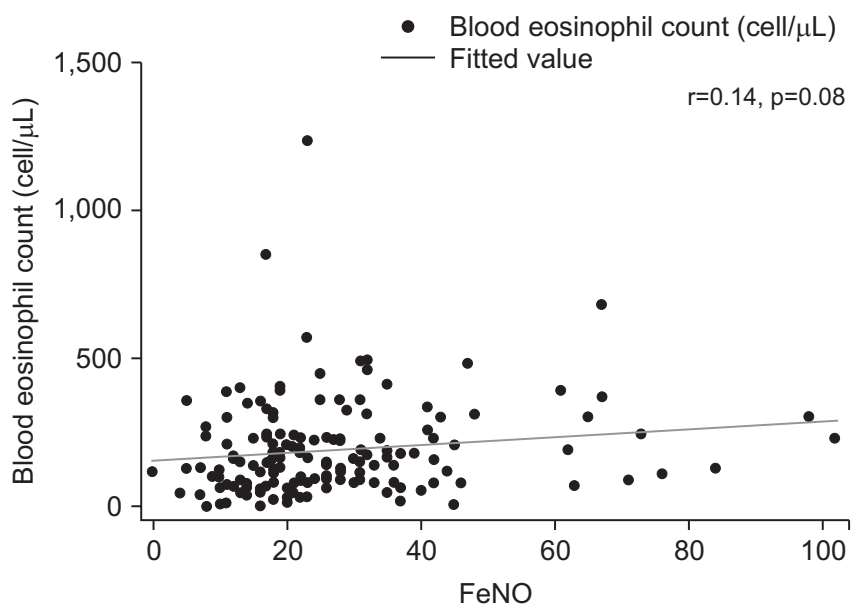

Figure 1. Correlation between blood eosinophil count and fractional exhaled nitric oxide (FeNO). there was no association between increased FeNO level and subjective wheezing alone in patients with COPD (Figure 2). When we used $\mathrm{FeNO} \geq 50 \mathrm{ppb}$, only a history of asthma without wheezing (OR, 4.87; 95\% CI, 1.34-17.67; $\mathrm{p}=0.016)$ was associated with FeNO $\geq 50$ ppb (Supplementary Figure S1).

\section{Prescription of ICS}

Among 160 COPD patients, 63 used ICS-containing inhalers before FeNO measurement. After FeNO measurement, 39 patients used ICS-containing inhalers and there was no statistical difference between patients with increased FeNO and normal FeNO ( 21 vs. 18 patients for $\mathrm{FeNO} \geq 25 \mathrm{ppb}$ and $<25 \mathrm{ppb}$, respectively; $\mathrm{p}=0.274$ ) (Table 3 ). The pattern of ICS prescription before and after FeNO measurements is shown in Figure 3. After FeNO measurements, only $57 \%$ of patients showed concordant prescription (given to increased FeNO group [ $\mathrm{n}=21]$ and not given to normal FeNO group [n=68]) of ICS-containing inhalers based on FeNO level. Among 63 patients with ICS-containing inhalers before FeNO measurement, ICS-containing inhalers were maintained in 19 patients (65.5\%) among those with increased FeNO, while ICS-containing inhalers were withdrawn in 10 patients (34.5\%) with increased FeNO. Among 18 patients who maintained ICScontaining inhalers despite of normal FeNO, seven (38.9\%) had experienced previous exacerbation before a year of enroll-

A

Clinical feature

COPD with wheezing

COPD \& BA without wheezing

COPD \& BA with wheezing

Clinical feature

COPD with wheezing

COPD \& BA without wheezing

COPD \& BA with wheezing
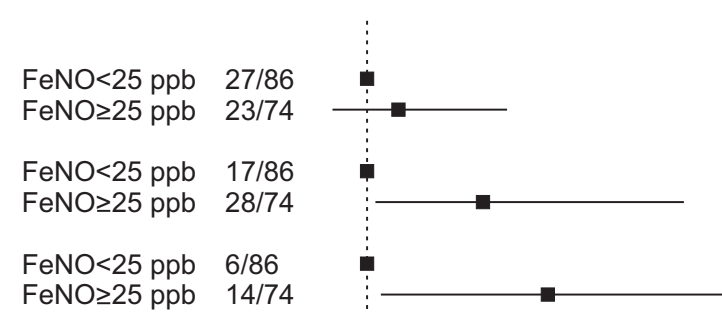
FeNO $\geq 25 \mathrm{ppb} 14 / 74$
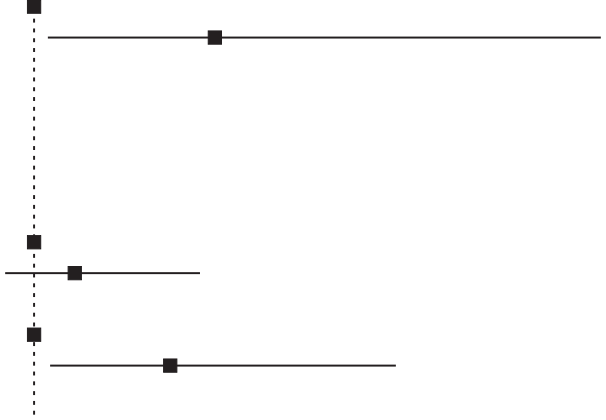
$3.11(1.23-8.57)$

$\begin{array}{cc}\text { OR }(95 \% \mathrm{Cl}) & \mathbf{p} \text {-value } \\ 1 \text { (reference) } & 0.966 \\ 0.99(0.50-1.93) & \\ 1 \text { (reference) } & 0.012 \\ 2.47(1.22-5.02) & \\ 1 \text { (reference) } & 0.028 \\ 3.11(1.23-8.57) & \end{array}$

aOR $(95 \% \mathrm{Cl})$ p-value

1 (reference) 1.07 (0.52-2.20) 0.848

1 (reference) $2.96(1.40-6.29)$ 0.005

1 (reference) $4.24(1.37-13.08) 0.012$

Figure 2. Forest plots for odds ratio (OR) of clinical phenotype according to patient classification based on fractional exhaled nitric oxide (FeNO) value: (A) unadjusted, and (B) adjusted data. Adjusted for age, sex, smoking status and forced expiratory volume in 1 second $<50 \%$ predicted. COPD: chronic obstructive pulmonary disease; ppb: parts per billion; BA: bronchial asthma; CI: confidence interval; aOR: adjusted OR. 
Table 3. Status of inhaled corticosteroid prescription before and after blood eosinophil and measurement of FeNO levels

\begin{tabular}{|ccc|}
\hline \multirow{2}{*}{ FeNO } & \multicolumn{2}{c|}{ Inhaled corticosteroid treatment } \\
\cline { 2 - 3 } & $\begin{array}{c}\text { Before FeNO } \\
\text { measurement }\end{array}$ & $\begin{array}{c}\text { After FeNO } \\
\text { measurement }\end{array}$ \\
\hline$<25 \mathrm{ppb}$ & $34(54.0)$ & $18(46.2)$ \\
\hline $25 \mathrm{ppb}$ & $29(46.0)$ & $21(53.9)$ \\
\hline p-value & 0.964 & 0.274 \\
\hline
\end{tabular}

Values are presented as number (\%).

FeNO: fractional exhaled nitric oxide; ppb: parts per billion.

ment and two (11.1\%) had a history of asthma and wheezing. On the other hand, among 97 patients without ICS-containing inhalers before FeNO measurement, ICS-containing inhalers were newly prescribed in two patients (4.4\%) with increased FeNO, whereas 43 patients $(95.6 \%)$ were maintained nonICS-containing inhaler despite of their increased FeNO (Figure 3). Among those 43 patients, 42 did not have a previous exacerbation history.

\section{Discussion}

In this study, we documented a significant association between increased FeNO levels ( $\geq 25 \mathrm{ppb}$ ) and history of bronchial asthma with or without combined wheezing in a COPD cohort, which persisted even after adjustments for age, sex, smoking status, and $\mathrm{FEV}_{1}<50 \%$ predicted. Clinicians' prescription decisions regarding ICS-containing inhalers in real-world clinical setting was not significantly differ between normal and increased FeNO groups but it appeared to be affected by clinical presentations such as previous exacerbation and history of asthma with accompanied wheezing.

Based on large-scale clinical trials, current guideline recommends ICS use to be combined with long-acting bronchodilators in patients who experience frequent exacerbations ${ }^{28}$. In addition, the use of ICS-containing inhalers demonstrated favorable response in terms of reduced exacerbations when the patients exhibited clinical features related to a high Th2cell signature including history of asthma and had objective parameters indicating eosinophilic airway inflammation ${ }^{29,30}$. However, clinicians in real-world setting often encounter ambiguous history due to recall bias of asthma and uncertain perception of wheezing. Although eosinophils in sputum and blood, as objective indicators for eosinophilic airway inflammation, have been investigated as a promising biomarker to predict the efficacy of ICS ${ }^{13,29}$, various hurdles, including limited accessibility to technicians for sputum eosinophils, and oscillating pattern on repeated testing of blood eosinophils $^{29,31,32}$, has impeded the use of these biomarkers in daily clinical practice.

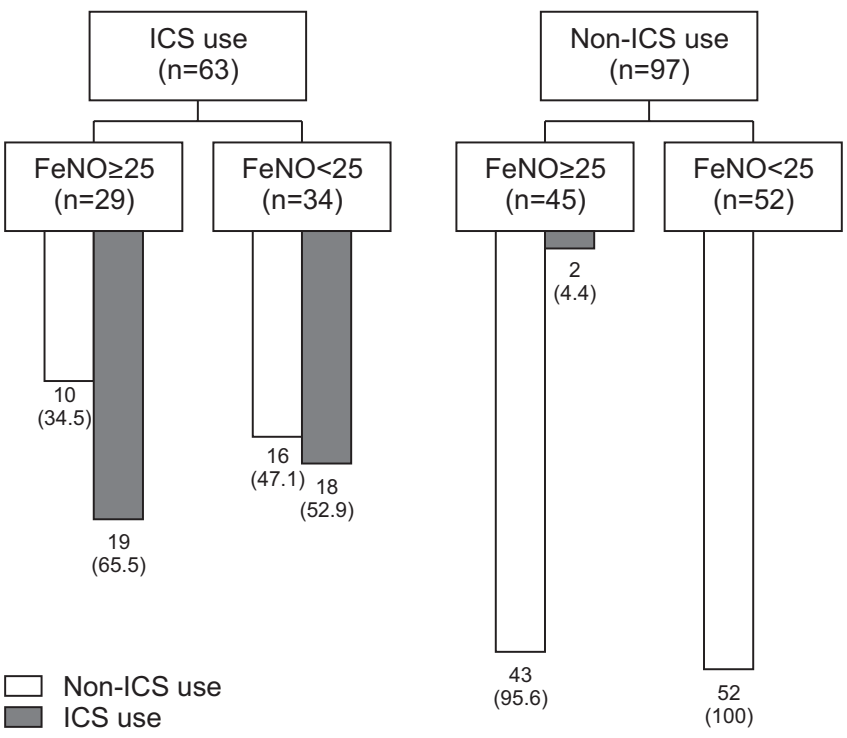

Figure 3. Changes in prescription status of inhaled corticosteroid (ICS) before and after measurement of fractional exhaled nitric oxide (FeNO) levels.

One of the alternative parameter reflecting eosinophilic airway inflammation is FeNO. Inducible nitric oxide synthase in the airway epithelium arises due to local inflammation during allergen exposure, leading to significant increase in NO levels ${ }^{33}$. Accordingly, the utility of FeNO has been highlighted in asthma and partly in COPD with exacerbations. In COPD exacerbations, patients with high FeNO levels at hospital admission are more likely to exhibit a favorable response with regard to lung function recovery at discharge ${ }^{34,35}$. Furthermore, we demonstrated that increased FeNO was independently associated with a history of asthma with or without wheezing, which was consistent with recent studies ${ }^{36,37}$. Thus, the role of FeNO in patients with stable COPD has attracted much attention from clinicians for guidance regarding ICS-containing inhaler therapy. Nevertheless, the clinical application of increased FeNO has not been fully investigated in real-world clinical practice in COPD.

To our knowledge, for the first time, we describe clinical applications of FeNO for the use of ICS-containing inhaler over short periods before and after FeNO measurement. Although ICS-containing inhalers were more frequently prescribed to patients whose FeNO value was increased, it was not clinically significant and FeNO value was not sole indicator to decide use of ICS-containing inhalers for clinicians. When we used FeNO $\geq 50 \mathrm{ppb}$, the similar trend was shown for the use of ICS-containing inhalers (Supplementary Figure S2). In other words, the physicians in real-world clinics tended to decide on the use of ICS-containing inhalers based on clinical presentation such as previous exacerbations or previous history of asthma and wheezing in addition to FeNO value. In particular, among those 43 patients, who maintained to use 
non-ICS-containing inhalers despite of their increased FeNO level, 42 patients did not have a previous exacerbation history. On the other hand, among 18 patients who maintained ICScontaining inhaler despite of normal FeNO, seven patients went through exacerbation and two had asthma history and accompanied wheezing. Those two patients who newly prescribed ICS-containing inhaler, had no previous exacerbation and one patients has asthma and wheezing, but their FeNO level was high. Thus, an integrated approach with clinical features including exacerbation history and suggestive of Th2 inflammation and level of $\mathrm{FeNO}$ is applied to clinical decision on the use of ICS-containing inhalers in real-world clinics.

There are several important limitations of the present study. First, FeNO level was measured using two NO analyzersNIOX MINO and NO breath-depending on the availability. However, diagnostic concordance between the two devices has been reported to be sufficiently high for clinical use ${ }^{38}$. Second, current smoking status and ICS use are known factors that could affect the level of $\mathrm{FeNO}^{39}$. Because this was an observational cohort study of COPD and small number of each subgroup did not allow us to draw significant conclusion due to insufficient statistical power, we included all patients, regardless of their smoking status (i.e., current smoker) and current ICS users. Third, there was a considerable number of patients who exhibited increased FeNO levels in our study compared with previous studies ${ }^{34,36}$. Because there were no criteria to measure FeNO in patients with COPD in the cohort, and measurement of FeNO was at the discretion of the treating respiratory specialist, there may have been potential selection bias. Finally, because we observed the clinical applications of FeNO over short periods and the effect of FeNO measurements on ICS prescription changes is ambiguous, further studies are needed to investigate the impact of FeNO level on clinical decisions of whether the use of ICS-containing inhalers or not and on future exacerbations over longerterm periods.

In conclusion, increased FeNO is significantly associated with clinical features representing type 2 inflammation. However, clinicians in real-world clinics appeared to regard FeNO as having a subsidiary role in the use of ICS-containing inhalers. Future studies are required to investigate long-term outcome based on level of FeNO, clinical presentations and use of ICS-containing inhalers, thereby assist in identifying ICS responders.

\section{*Author Affiliations}

${ }^{1}$ Division of Pulmonary, Allergy, and Critical Care Medicine, Department of Internal Medicine, Hallym University Kangdong Sacred Heart Hospital, Seoul, ${ }^{2}$ Division of Pulmonary and Critical Care Medicine, Department of Medicine, Samsung Medical Center, Sungkyunkwan
University School of Medicine, Seoul, ${ }^{3}$ Division of Pulmonary and Critical Care Medicine, Department of Internal Medicine, Ilsan Paik Hospital, Inje University College of Medicine, Goyang, ${ }^{4}$ Division of Pulmonary, Allergy, and Critical Care Medicine, Department of Internal Medicine, Yonsei University Wonju Severance Christian Hospital, Yonsei University Wonju College of Medicine, Wonju, ${ }^{5}$ Department of Internal Medicine, Chonnam National University Hospital, Gwangju, ${ }^{6}$ Department of Medicine, Ulsan University Hospital, University of Ulsan College of Medicine, Ulsan, ${ }^{7}$ Division of Pulmonary and Allergy Medicine, Department of Internal Medicine, Konkuk University School of Medicine, Seoul, ${ }^{8}$ Divsion of Pulmonary, Allergy and Critical Care Medicine, Department of Internal Medicine, Hallym University Sacred Heart Hospital, Anyang, ${ }^{9}$ Division of Pulmonary, Allergy, and Critical Care Medicine, Department of Internal Medicine, Hallym University Kangdong Sacred Heart Hospital, Seoul, Korea

\section{Authors' Contributions}

Conceptualization: Park HY, Park YB. Methodology: Jo YS, Park HY, Park YB. Formal analysis: Jo YS. Data curation: Jo YS, Choe J. Investigation: Jo YS, Choe J, Shin SH, Koo HK, Lee WY, Kim YI, Ra SW, Yoo KH, Jung KS, Park HY, Park YB. Writing original draft preparation: Jo YS. Writing - review and editing: Jo YS, Park HY, Park YB. Approval of final manuscript: all authors.

\section{Conflicts of Interest}

No potential conflict of interest relevant to this article was reported.

\section{Funding}

No funding to declare.

\section{Supplementary Material}

Supplementary material can be found in the journal homepage (http://www.e-trd.org).

Supplementary Figure S1. Forest plots for odds ratio of clinical phenotype by patient classification according to fractional exhaled nitric oxide (FeNO) value of $50 \mathrm{ppb}$.

Supplementary Figure S2. Changes in prescription status of inhaled corticosteroid (ICS) before and after measurement of fractional exhaled nitric oxide (FeNO) levels by FeNO value of $50 \mathrm{ppb}$. 


\section{References}

1. Bellocchia M, Masoero M, Ciuffreda A, Croce S, Vaudano A, Torchio R, et al. Predictors of cardiovascular disease in asthma and chronic obstructive pulmonary disease. Multidiscip Respir Med 2013;8:58.

2. Price D, West D, Brusselle G, Gruffydd-Jones K, Jones R, Miravitlles $\mathrm{M}$, et al. Management of COPD in the UK primarycare setting: an analysis of real-life prescribing patterns. Int J Chron Obstruct Pulmon Dis 2014;9:889-904.

3. Vestbo J, Vogelmeier C, Small M, Higgins V. Understanding the GOLD 2011 Strategy as applied to a real-world COPD population. Respir Med 2014;108:729-36.

4. Worth H, Buhl R, Criee CP, Kardos P, Mailander C, Vogelmeier C. The 'real-life' COPD patient in Germany: The DACCORD study. Respir Med 2016;111:64-71.

5. Eriksson KO, Naidu AS, Kilar F, Wadstrom T, Hjerten S. Surface hydrophobicity and electrophoretic mobilities of staphylococcal exotoxins with special reference to toxic shock syndrome toxin-1. APMIS 1989;97:1081-7.

6. Gonzalez AV, Coulombe J, Ernst P, Suissa S. Long-term use of inhaled corticosteroids in COPD and the risk of fracture. Chest 2018;153:321-8.

7. Price D, Yawn B, Brusselle G, Rossi A. Risk-to-benefit ratio of inhaled corticosteroids in patients with COPD. Prim Care Respir J 2013;22:92-100.

8. Di Stefano A, Capelli A, Lusuardi M, Balbo P, Vecchio C, Maestrelli $\mathrm{P}$, et al. Severity of airflow limitation is associated with severity of airway inflammation in smokers. Am J Respir Crit Care Med 1998;158:1277-85.

9. Saha S, Brightling CE. Eosinophilic airway inflammation in COPD. Int J Chron Obstruct Pulmon Dis 2006;1:39-47.

10. Christenson SA, Steiling K, van den Berge M, Hijazi K, Hiemstra PS, Postma DS, et al. Asthma-COPD overlap. Clinical relevance of genomic signatures of type 2 inflammation in chronic obstructive pulmonary disease. Am J Respir Crit Care Med 2015;191:758-66.

11. Barnes PJ. Therapeutic approaches to asthma-chronic obstructive pulmonary disease overlap syndromes. J Allergy Clin Immunol 2015;136:531-45.

12. Brightling CE, Monteiro W, Ward R, Parker D, Morgan MD, Wardlaw AJ, et al. Sputum eosinophilia and short-term response to prednisolone in chronic obstructive pulmonary disease: a randomised controlled trial. Lancet 2000;356:14805.

13. Brightling CE, McKenna S, Hargadon B, Birring S, Green $\mathrm{R}$, Siva R, et al. Sputum eosinophilia and the short term response to inhaled mometasone in chronic obstructive pulmonary disease. Thorax 2005;60:193-8.

14. Bafadhel M, McKenna S, Terry S, Mistry V, Pancholi M, Venge $\mathrm{P}$, et al. Blood eosinophils to direct corticosteroid treatment of exacerbations of chronic obstructive pulmonary disease: a randomized placebo-controlled trial. Am J Respir Crit Care
Med 2012;186:48-55.

15. Barnes NC, Sharma R, Lettis S, Calverley PM. Blood eosinophils as a marker of response to inhaled corticosteroids in COPD. Eur Respir J 2016;47:1374-82.

16. Negewo NA, McDonald VM, Baines KJ, Wark PA, Simpson JL, Jones PW, et al. Peripheral blood eosinophils: a surrogate marker for airway eosinophilia in stable COPD. Int J Chron Obstruct Pulmon Dis 2016;11:1495-504.

17. Bafadhel M, Peterson S, De Blas MA, Calverley PM, Rennard SI, Richter K, et al. Predictors of exacerbation risk and response to budesonide in patients with chronic obstructive pulmonary disease: a post-hoc analysis of three randomised trials. Lancet Respir Med 2018;6:117-26.

18. Global Initiative for Chronic Obstructive Lung Disease. Global strategy for the diagnosis, management, and prevention of chronic obstructive pulmonary disease: 2019 update [Internet]. Fontana, WI: Global Initiative for Chronic Obstructive Lung Disease; 2019 [cited 2019 Feb 15]. Available from: http://www.goldcopd.org.

19. Shin SH, Park HY, Kang D, Cho J, Kwon SO, Park JH, et al. Serial blood eosinophils and clinical outcome in patients with chronic obstructive pulmonary disease. Respir Res 2018; 19:134.

20. Southworth T, Beech G, Foden P, Kolsum U, Singh D. The reproducibility of COPD blood eosinophil counts. Eur Respir J 2018;52:1800427.

21. Jatakanon A, Lim S, Kharitonov SA, Chung KF, Barnes PJ. Correlation between exhaled nitric oxide, sputum eosinophils, and methacholine responsiveness in patients with mild asthma. Thorax 1998;53:91-5.

22. Berlyne GS, Parameswaran K, Kamada D, Efthimiadis A, Hargreave FE. A comparison of exhaled nitric oxide and induced sputum as markers of airway inflammation. J Allergy Clin Immunol 2000;106:638-44.

23. Price DB, Buhl R, Chan A, Freeman D, Gardener E, Godley $\mathrm{C}$, et al. Fractional exhaled nitric oxide as a predictor of response to inhaled corticosteroids in patients with nonspecific respiratory symptoms and insignificant bronchodilator reversibility: a randomised controlled trial. Lancet Respir Med 2018;6:29-39.

24. Lee JY, Chon GR, Rhee CK, Kim DK, Yoon HK, Lee JH, et al. Characteristics of patients with chronic obstructive pulmonary disease at the first visit to a pulmonary medical center in Korea: The KOrea COpd Subgroup Study Team Cohort. J Korean Med Sci 2016;31:553-60.

25. Pellegrino R, Viegi G, Brusasco V, Crapo RO, Burgos F, Casaburi R, et al. Interpretative strategies for lung function tests. Eur Respir J 2005;26:948-68.

26. Choi JK, Paek D, Lee JO. Normal predictive values of spirometry in Korean population. Tuberc Respir Dis 2005;58:230-42.

27. Dweik RA, Boggs PB, Erzurum SC, Irvin CG, Leigh MW, Lundberg JO, et al. An official ATS clinical practice guideline: interpretation of exhaled nitric oxide levels (FENO) for clinical 
applications. Am J Respir Crit Care Med 2011;184:602-15.

28. Kim JH, Yim JJ. Achievements in and challenges of tuberculosis control in South Korea. Emerg Infect Dis 2015;21:1913-20.

29. Pavord ID, Lettis S, Locantore N, Pascoe S, Jones PW, Wedzicha JA, et al. Blood eosinophils and inhaled corticosteroid/ long-acting beta-2 agonist efficacy in COPD. Thorax 2016; 71:118-25.

30. Su VY, Yang KY, Yang YH, Tsai YH, Perng DW, Su WJ, et al. Use of ICS/LABA combinations or LAMA is associated with a lower risk of acute exacerbation in patients with coexistent COPD and asthma. J Allergy Clin Immunol Pract 2018;6:192735 .

31. Oshagbemi OA, Burden AM, Braeken DC, Henskens Y, Wouters EF, Driessen JH, et al. Stability of blood eosinophils in patients with chronic obstructive pulmonary disease and in control subjects, and the impact of sex, age, smoking, and baseline counts. Am J Respir Crit Care Med 2017;195:1402-4.

32. Vedel-Krogh S, Nielsen SF, Lange P, Vestbo J, Nordestgaard BG. Blood eosinophils and exacerbations in chronic obstructive pulmonary disease. The Copenhagen General Population Study. Am J Respir Crit Care Med 2016;193:965-74.

33. Dweik RA, Comhair SA, Gaston B, Thunnissen FB, Farver
C, Thomassen MJ, et al. NO chemical events in the human airway during the immediate and late antigen-induced asthmatic response. Proc Natl Acad Sci U S A 2001;98:2622-7.

34. Antus B, Barta I, Horvath I, Csiszer E. Relationship between exhaled nitric oxide and treatment response in COPD patients with exacerbations. Respirology 2010;15:472-7.

35. Soter S, Barta I, Antus B. Predicting sputum eosinophilia in exacerbations of COPD using exhaled nitric oxide. Inflammation 2013;36:1178-85.

36. Colak Y, Afzal S, Nordestgaard BG, Marott JL, Lange P. Combined value of exhaled nitric oxide and blood eosinophils in chronic airway disease: the Copenhagen General Population Study. Eur Respir J 2018;52;1800616.

37. Chen FJ, Huang XY, Liu YL, Lin GP, Xie CM. Importance of fractional exhaled nitric oxide in the differentiation of asthma-COPD overlap syndrome, asthma, and COPD. Int J Chron Obstruct Pulmon Dis 2016;11:2385-90.

38. Antus B, Horvath I, Barta I. Assessment of exhaled nitric oxide by a new hand-held device. Respir Med 2010;104:1377-80.

39. Kharitonov SA, Barnes PJ. Exhaled markers of pulmonary disease. Am J Respir Crit Care Med 2001;163:1693-722. 